\title{
Nocebo effects in practice: methotrexate myths and misconceptions
}

\author{
Providing patients with accurate information will help overcome obstacles to the \\ use of an effective treatment for rheumatoid arthritis
}

W eekly low dose methotrexate is the first-line agent and arguably an essential disease-modifying antirheumatic drug (DMARD) in the treatment of rheumatoid arthritis (RA). Australian rheumatologists' practice mirrors the recommendations of international rheumatology associations ${ }^{2-4}$ for early treatment with methotrexate, often combined with other DMARDs. A trial of methotrexate in combination with other DMARDs is an Australian prerequisite for therapy with biological disease-modifying drugs. About $20 \%$ of more than 3.4 million Pharmaceutical Benefits Scheme-subsidised DMARD prescriptions issued between 2003 and 2007 to 236000 Australians for the treatment of RA were for methotrexate. ${ }^{5}$ As older agents such as injectable gold, azathioprine and cyclosporine fall out of favour, methotrexate usage will likely increase, not only for treatment of RA but also other rheumatological and inflammatory conditions such as psoriatic arthritis, juvenile idiopathic arthritis and systemic vasculitis.

Knowledge of the pharmacology of methotrexate is important to understand its potential toxicity. The interindividual bioavailability of oral methotrexate is about $70 \%$. Oral absorption of methotrexate can be variable at doses above 15-20 mg/week; hence parenteral administration may be appropriate in cases of apparent inefficacy or problematic tolerability. The serum half-life of methotrexate is between 6 and 8 hours following administration, $70 \%$ is eliminated unchanged by renal excretion, and it is undetectable after 24 hours. ${ }^{1}$ Methotrexate is not lipophilic ${ }^{6}$ and thus cannot be absorbed via the skin, whether in solid form (tablet) or liquid (solution for injection). Co-treatment with folate is recommended by a recent systematic review, in support of rheumatology association guidelines to reduce gastrointestinal side effects, mucositis, transaminitis and treatment discontinuations.

Significant and avoidable toxicity, resulting in mortality, typically from inappropriate daily rather than weekly schedules and/or dosage errors, has been highlighted. While we agree that the potential for dosage and administration errors must be appreciated and eliminated, methotrexate is an indispensable medication for the treatment of RA as monotherapy or in combination. ${ }^{9}$

Nocebo effects are "biologically implausible negative effects of active therapies" that may arise from the anticipation of adverse effects from any intervention. ${ }^{10}$ There are several methotrexate "myths" that may be held by patients and health professionals, and propagated through word of mouth, information in print ${ }^{11}$ or on the internet that, if not simply inaccurate, may be contextually inappropriate and may generate prominent nocebo effects. Such negative anticipation responses - the

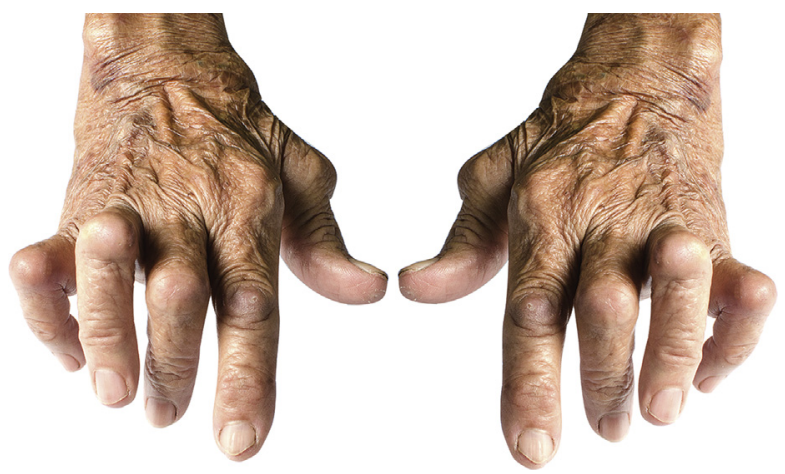

expectation of routine adverse effects - may result in objections to treatment and misinterpretation and misattribution of symptoms developing during a treatment regimen. This can result in poor treatment adherence and potentially avoidable suboptimal patient outcomes. Routinely available consumer medical information leaflets ${ }^{12}$ list many adverse effects and may prove unnecessarily disturbing to patients for whom methotrexate is recommended. This is a particularly likely outcome if these written materials are used as a proxy or even a substitute for genuine discussion with the treating doctor.

In this article, we highlight commonly held myths and misconceptions regarding methotrexate treatment. We advocate that these be discussed with patients to assist in making appropriate decisions based on accurate and, most importantly, contextually relevant information.

\section{Methotrexate myths}

\section{Methotrexate (for non-malignant diseases) is chemotherapy}

Chemotherapy regimens for neoplasia may utilise cycling protocols where methotrexate may be used as monotherapy or in combination with other cytotoxics where single dosages might exceed $500 \mathrm{mg} / \mathrm{m}^{2}$. For rheumatic diseases, methotrexate is typically used in low dose weekly oral or parenteral regimens, in doses ranging from 10 to $30 \mathrm{mg}$ weekly, usually less than $10 \mathrm{mg} / \mathrm{m}^{2}$ weekly. ${ }^{9}$

\section{Methotrexate is unusual or strong treatment}

Both the European League Against Rheumatism ${ }^{2}$ and the American College of Rheumatology ${ }^{3}$ recommend early treatment with methotrexate for RA. Methotrexate can be described as safe and efficacious, rather than unusual, treatment and has been in use since the mid-1980. ${ }^{13,14}$ The concept of gaining control of inflammatory arthritis as early as possible to prevent joint damage and disability is compelling, and the words "strong" or, preferably, 
"effective" used in that context can be seen as much more positive and accurate.

Patients should not be co-prescribed non-steroidal anti-inflammatory drugs and methotrexate

Methotrexate is often prescribed along with non-selective non-steroidal anti-inflammatory drugs (NSAIDs) or cyclooxygenase- 2 inhibitors to achieve analgesic and antiinflammatory effects in addition to the disease-modifying effect of methotrexate; however, there is a common automatic alert generated in prescribing software and pharmacies, which can lead to confusion for patients. This myth may also be propagated through the internet via blogs and other grey sources.

However, there are no specific grounds to unreservedly prohibit the combination of NSAIDs and methotrexate. ${ }^{15}$

The context of compromised renal function deserves specific mention owing to the renal clearance of methotrexate. Renal function should be monitored and the dose of methotrexate appropriately adjusted. Patients are often unnecessarily alarmed by advice from health professionals to avoid this drug combination at all costs, and this may contribute to the nocebo effect.

\section{Third parties must avoid (any) exposure to the body fluids of methotrexate-treated patients}

Patients may be told by health professionals or lay persons to carefully dispose of their urine and faeces, avoid kissing, cuddling or nursing infants and children, and avoid both non-intimate and intimate kissing.

The warning to avoid any contact with pregnant women is so important that it is dealt with separately below.

Such statements conflate the concept of "methotrexate as chemotherapy" and the notion that "all cytotoxics are the same" in the absence of specific data pertaining to low dose weekly methotrexate for RA. Normal standards of personal hygiene are the principal safeguard for third parties.

\section{Patients receiving methotrexate should avoid contact with pregnant women}

Methotrexate is a pregnancy category $X$ drug (exposure to which has a substantial risk of causing permanent damage to the fetus) and should not be administered to pregnant women or those with reproductive capacity unless reliable contraception measures are employed. There is a clear risk of congenital abnormalities in babies exposed to methotrexate in the first trimester.

However, the potential of a pregnant woman to have sufficient exposure to methotrexate from social contact with a methotrexate-treated individual with RA is negligible. ${ }^{16}$ Therefore, there is also a negligible risk in already pregnant women exposed to partners' body fluids.

\section{Misconceptions regarding parenteral methotrexate injections}

Unlike in Australia, in the United States and the United Kingdom, methotrexate is commercially available as a pre-packaged preparation. Methotrexate has been administered via subcutaneous or intramuscular routes for RA since its introduction. ${ }^{1}$ Much of the problematic advice given to patients pertains to parenteral methotrexate. The most common are as follows.

\section{Methotrexate injections must be prepared by an oncology pharmacist and administered by an oncology nurse}

This misconception results from misreading and misapplying cytotoxic preparation and administration guidelines. Certainly methotrexate as chemotherapy must be so prepared under these guidelines. ${ }^{17}$ The guidelines do not refer to the specific context of low dose administration in non-neoplastic diseases. Methotrexate is neither a vesicant nor an irritant ${ }^{18,19}$ and is not an extravasation risk. ${ }^{20}$

\section{Eye, mask and glove, and gown precautions are mandatory for staff administering injected methotrexate}

Universal precautions and post-needlestick procedures are mandatory. If, despite universal precautions, a needle stick injury occurs, the amount of injected methotrexate is small and most likely equivalent to the dead space in a syringe $(0.1 \mathrm{~mL}$ of the usual methotrexate concentration equates to a $2 \mathrm{mg}$ dose).

Trace methotrexate exposures could be anticipated through contact with methotrexate-treated RA patients' saliva, tears or urine ${ }^{21}$ or faecal material, ${ }^{22}$ but the practical likelihood of such exposure resulting in methotrexate toxicity is likely to be negligible with conventional personal hygiene.

If staff are unwilling to administer injectable methotrexate to RA patients, despite the above, self-administration should be recommended.

\section{Self-administration is impractical and potentially unsafe}

Self-injection can be safely recommended and instituted with appropriate education in RA patients treated with methotrexate, ${ }^{23}$ and this results in increased patient satisfaction relating to time-saving and convenience. ${ }^{24}$

Self-administration will obviate any potential concerns regarding exposure to third parties and should be encouraged where possible if parenteral administration is indicated.

\section{Methotrexate should not be administered by pregnant health care workers}

There is no specific evidence that health care workers with reproductive capacity are harmed by administering methotrexate for RA. Regarding male staff administering methotrexate, there is no record of increased fetal abnormalities in the offspring of men treated with methotrexate. Hence, there is no quantifiable reproductive risk to any worker or their partner from administering parenteral low dose methotrexate to RA patients. ${ }^{25,26}$

\section{Summary}

To improve trust, patient engagement, treatment adherence and therapeutic outcomes, nocebo-generating notions regarding methotrexate should be discussed openly with patients at the initiation of and during treatment. 
1 Cronstein BN. Low-dose methotrexate: a mainstay in the treatment of rheumatoid arthritis. Pharmacol Rev 2005; 57: 163-172.

2 Smolen JS, Landewe R, Breedveld FC, et al. EULAR recommendations for the management of rheumatoid arthritis with synthetic and biological disease-modifying antirheumatic drugs: 2013 update. Ann Rheum Dis 2014: 73: 492-509.

3 Singh JA, Saag KG, Bridges SL, et al. 2015 American College of Rheumatology guideline for the treatment of rheumatoid arthritis. Arthritis Rheumatol 2016; 68: 1-26.

4 Bykerk VP, Akhavan P. Hazlewood GS, et al. Canadian Rheumatology Association recommendations for pharmacological management of rheumatoid arthritis with traditional and biologic disease-modifying antirheumatic drugs. J Rheumatol 2012; 39: 1559-1582.

5 Australian Institute of Health and Welfare. The use of disease-modifying anti-rheumatic drugs for the management of rheumatoid arthritis (AlHW Cat. No. PHE 138; Arthritis Series No. 16). Canberra: AlHW, 2011. (www.aihw.gov.au/WorkArea/DownloadAsset.aspx?id=10737418562\&libID)

6 Rosowsky A, Lazarus H, Yuan GC, et al. Effects of methotrexate esters and other lipophilic antifolates on methotrexate-resistant human leukemic lymphoblasts. Biochem Pharmacol 1980; 29: 648-652.

7 Shea B, Swinden MV, Ghogomu ET, et al. Folic acid and folinic acid for reducing side effects in patients receiving methotrexate for rheumatoid arthritis. J Rheumatol 2014; 41: 1049-1060.

8 Cairns R, Brown JA, Lynch AM, et al. A decade of Australian methotrexate dosing errors. Med J Aust 2016; 204: 384. https://www.mja.com.au/journal/ 2016/204/10/decade-australian-methotrexate-dosing-errors

9 Hazlewood GS, Barnabe C, Tomlinson G, et al. Methotrexate monotherapy and methotrexate combination therapy with traditional and biologic disease modifying antirheumatic drugs for rheumatoid arthritis: abridged Cochrane systematic review and network meta-analysis. BMJ 2016; 353: il777.

10 Arnold MH, Finniss DG, Kerridge I. Medicine's inconvenient truth: the placebo and nocebo effect. Intern Med J 2014; 44: 398-405.

11 Tan K, Petrie KJ, Faasse K, et al. Unhelpful information about adverse drug reactions. BMJ 2014; 349: g5019.

12 NPS MedicineWise. Health professionals urged to be alert to methotrexate risks [media release]. 20 Dec 2011. http://www.nps.org. au/_data/assets/pdf_file/0003/136812/Media_release_-_Methotrexate_-Dec 2011_FINAL.pdf
13 Abasolo L, Leon L, Rodriguez-Rodriguez L, et al. Safety of disease-modifying antirheumatic drugs and biologic agents for rheumatoid arthritis patients in real-life conditions. Semin Arthritis Rheum 2015; 44: 506-513.

14 Lopez-Olivo MA, Siddhanamatha HR, Shea B, et al. Methotrexate for treating rheumatoid arthritis. Cochrane Database Syst Rev 2014; (6): CD000957.

15 Colebatch AN, Marks JL, van der Heijde DM, Edwards CJ. Safety of nonsteroidal antiinflammatory drugs and/or paracetamol in people receiving methotrexate for inflammatory arthritis: a Cochrane systematic review. J Rheumatol 2012; 90: 62-73.

16 Weber-Schoendorfer C, Hoeltzenbein M, Wacker E, et al. No evidence for an increased risk of adverse pregnancy outcome after paternal low-dose methotrexate: an observational cohort study. Rheumatology (Oxford) 2014; 53: 757-763.

17 Sydney Children's Hospital. Cytotoxic and hazardous drugs: administration and handling - SCH. Procedure No 1/C/13:7025-01:01. http://www.schn. health.nsw.gov.au/_policies/pdf/2013-7025.pdf (accessed July 2016).

18 Azaïs $\mathrm{H}$, Bresson L, Bassil A, et al. Chemotherapy drug extravasation in totally implantable venous access port systems: how effective is early surgical lavage? J Vasc Access 2014; 16: 31-37.

19 Sauerland C, Engelking C, Wickham R, Corbi D. Vesicant extravasation part I: mechanisms, pathogenesis, and nursing care to reduce risk. Oncol Nurs Forum 2006; 33: 1134-1141.

20 Ang TS, Siderov J. Extravasation of high-dose methotrexate. A case about nothing. Aust J Hosp Pharm 1998; 28: 430-431.

21 Steele WH, Stuart JF, Whiting B, et al. Serum, tear and salivary concentrations of methotrexate in man. Br J Clin Pharmacol 1979; 7: 207-211.

22 Huffman DH, Wan SH, Azarnoff DL, Hoogstraten B. Pharmacokinetics of methotrexate. Clin Pharmacol Ther 1973; 14(4part1): 572-579.

23 Arthur V, Jubb R, Homer D. A study of parenteral use of methotrexate in rheumatic conditions. J Clin Nurs 2002; 11: 256-263.

24 Arthur AB, Klinkhoff AV, Teufel A. Safety of self-injection of gold and methotrexate. J Rheumatol 1999; 26: 302-305.

25 Dranitsaris G, Johnston M, Poirier S, et al. Are health care providers who work with cancer drugs at an increased risk for toxic events? A systematic review and meta-analysis of the literature. J Oncol Pharm Pract 2005; 11: 69-78.

26 Fransman W, Roeleveld N, Peelen S, et al. Nurses with dermal exposure to antineoplastic drugs: reproductive outcomes. Epidemiology 2007; 18: 112-119. 